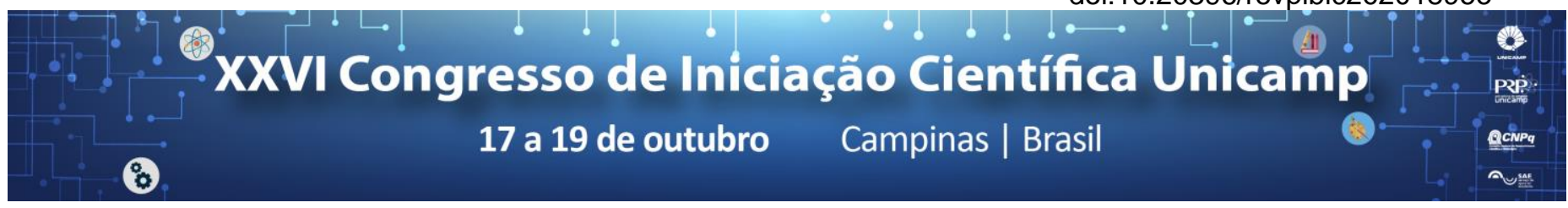

\title{
JET CUTTER AS TOOL TO IMMOBILIZE LIPASE FOR BIODIESEL PRODUCTION
}

\section{Marcelo D’Elia Feliciano*, Beatriz Travalia, Marcus Bruno Soares Forte, Ana Silvia Prata.}

\begin{abstract}
The use of lipases as a biocatalyst for industrial applications is an interesting route due to technical aspects but also to reduce environmental impacts caused by the use of chemical catalysts. Gel immobilization of the enzyme allows its reuse and avoids contamination of the product with residual portions of free enzyme. However, a typical technique available for enzyme immobilization is based on dripping driven by gravity which produces big particles and low rate of production. The reduction of size can improve the mass transfer by increasing the contact area. Thus, aiming to increase the rate of particles production and reduce the size of particles, the objective of this work was to encapsulate lipase, using a tool designed to cut the jet produced by pumping, called as Jet Cutter.
\end{abstract}

Key words: Lipase, Immobilization, Jet Cutter.

\section{Introduction}

Enzymes, used as esterification catalysts for oils and fats, may be used in free or immobilized form. The use of the immobilized enzyme favors an economic gain in the process, because it allows reuse of the biocatalyst and avoids product contamination with residual portions of free enzyme (JEGANNATHAN et al., 2010). For the immobilization, the formation of the particles by ionic gelling causes positive results in the stability of the enzymes (JEGANNATHAN et al., 2009).

The challenge of developing a scalable, smaller particle-producing process can be overcome with the use of the Jet Cutter, which can reduce the particles to diameters smaller than $1 \mathrm{~mm}$ (PAULO et al., 2017).

\section{Results and Discussion}

The effect of lyophilization on the enzymatic activities of the particles was evaluated, since the hydrophilic network associated with the formation of alginate gels may be an interferer in the lipolytic activity (Image1).

As lyophilized particles ( $2 \%$ alginate) showed considerably higher activity than non-lyophilized one, only lyophilized particles were analyzed for enzymatic activity with $1.5 \%$ alginate. It is observed that the particles with $1.5 \%$ of alginate presented a superior activity, demonstrating that the immobilization by jet cutter was favorable to formation of a more active biocatalyst.

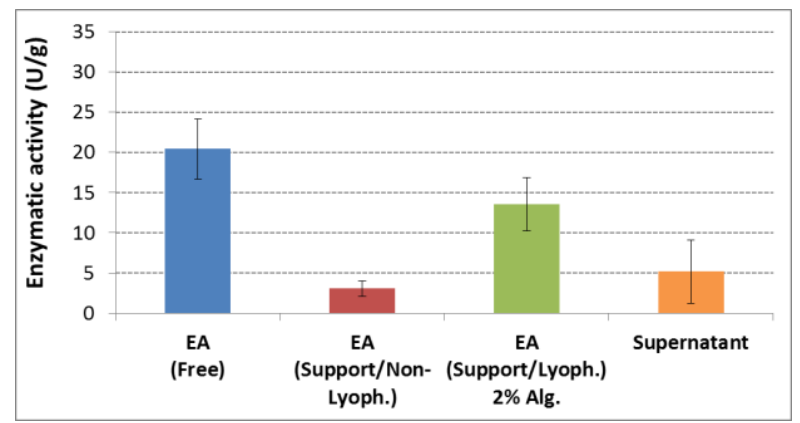

Image 1. Enzymatic activities of free and immobilized (lyophilized and non-lyophilized) lipases: $2 \%$ alginate.

The biocatalyst obtained by immobilization process showed a very interesting activity in comparison to the free enzyme $\left(E A_{\exp }=29.0 \mathrm{U} / \mathrm{g}\right)$, a $69 \%$ more activity biocatalyst.

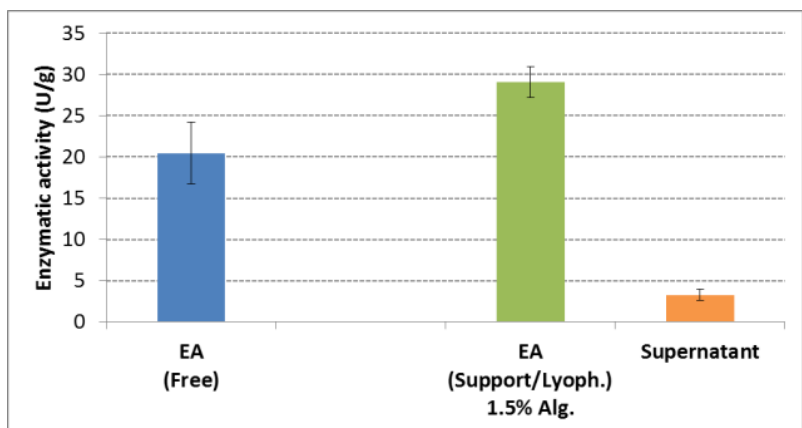

Image 2. Enzymatic activities of free and immobilized (lyophilized) lipases: 1.5\% alginate.

The results are associated with: the effect of the jet cutter, which may be exposing the active sites of the enzyme; to a more selective immobilization of the lipase, obtaining a more pure biocatalyst; and to the subsequent lyophilization process which, in addition to circumventing the hydrophilic network obstacle of the alginate matrix, decreased the mass transport resistance on the particle.

\section{Conclusions}

It is possible to conclude that jet cutter technique has demonstred a very good efficiency and presented as a great alternative in the immobilization of Lipozyme ${ }^{\circledR}$ CALB L lipase. As a continuation of this research, the group is carrying out the investigation about the enzyme stability (half-life time) and thermal stability (denaturation energy) for free and immobilized enzymes.

\section{Acknowledgement}

The authors are grateful to PRP/UNICAMP and CNPq for the scientific initiation grant.

Jegannathan, K. R.; Jun-Yee, L.; Chan, E.S.; Ravindra, P. (2009) Design an immobilized lipase enzyme for biodiesel production. Journal of Renewable and Sustainable Energy, v. 1, n. 6, p. 63101.

Jegannathan, K. R.; Jun-Yee, L.; Chan, E.S.; Ravindra, P. (2010) Production of biodiesel from palm oil using liquid core lipase encapsulated in $\kappa$-carrageenan. Fuel, v. 89, n. 9, p. 2272-2277.

Paulo, B. B.; Melo, F. DE; Ana, R.; Prata, S. (2017) An investigation of operational parameters of jet cutting method on the size of Ca-alginate, beads $n$. February, p. 1-8. 